\title{
Enthesopathic patterns of two South African female cadavers
}

\author{
N. Naidoo ${ }^{1}$ L. Lazarus², K.S. Satyapal ${ }^{2}$ \\ ${ }^{1}$ College of Medicine, Mohammed Bin Rashid University of Medicine and Health Sciences, Dubai Healthcare City, \\ Dubai, United Arab Emirates \\ 2Department of Clinical Anatomy, School of Laboratory Medicine and Medical Sciences, College of Health Sciences, \\ University of KwaZulu-Natal, Westville Campus, Durban, South Africa
}

[Received: 7 August 2014; Accepted: 28 September 2014]

\begin{abstract}
Enthesopathy is considered to be an osseous phenomenon, either disease-specific or bone-site specific, which occurs at the enthesis of bone. Upon routine cadaveric dissection of the glenohumeral region in two Caucasian females, enthesopathy of the right proximal humerus was observed unilaterally in both cases.

Case 1 exhibited an inconsistent pattern of bony protuberances and crests dispersed across the lesser and greater tuberosities of the right humeral head. Varying degrees of ossification of the distal subscapularis muscle was also observed. Case 2 presented with a distinctively large enthesophyte that protruded supero-medially from the proximal right humerus. In addition, ossification of the distal-most aspect of the supraspinatus muscle was identified. Cases 1 and 2 were both reflective of osteophytic enthesopathy as proliferative change was clearly visible on the proximal aspect of each humerus.

Whilst the presence of enthesopathies may be indicative of underlying pathology, it may prove beneficial to the field of bioarchaeology for the remodelling of lifestyles of ancient civilizations through the provision of current day variations as seen in these two case studies. (Folia Morphol 2017; 76, 2: 326-330)
\end{abstract}

Key words: enthuses, enthesopathy, proximal humerus, osteophytic

\section{INTRODUCTION}

The osseous insertion site of a tendon, muscle, ligament, fascia and/or articular capsule is referred to as an enthesis $[14,17,22]$. Since the enthesis is a hybrid tissue composed of cartilage and collagen fibres, it may be classified as fibrous or fibrocartilaginous depending on the nature of the tissue at that particular skeletal insertion site $[2-4,10,12,23]$. Enthesopathy is regarded as one of the three main types of pathological degeneration occurring at articular regions $[8.9,17]$. Although enthesopathies are considered to be important musculoskeletal markers of human skeletal remains in the field of paleontology, the clinical focus is attributed to the underlying traumatic, metabolic, inflammatory, degenerative and endocrine diseases $[1,9,11,17,21,22]$. Mariotti et al. [14] described enthesopathies as osteophytic, displaying proliferative change, and osteolytic, that of which is characterised by erosion. Enthesopathies thus differ morphologically from minute crests and elevations to prominently large bony spurs [22].

Due to the peripheral and spinal nature of entheses, enthesopathies have been reported to affect skeletal sites of the pelvis, humeral head, femoral trochanter, patella, vertebral column, olecranon of the ulnar and the calcaneus [17, 22]. Many studies have documented the presence of enthesopathies

Address for correspondence: Prof. K.S. Satyapal, Department of Clinical Anatomy, School of Laboratory Medicine and Medical Sciences, College of Health Sciences, University of KwaZulu-Natal, Private Bag X54001, Durban, 4000, South Africa, tel: $+27312607110 ;+27837778780$, fax: + 2731260 7890, e-mail: satyapalk@ukzn.ac.za 


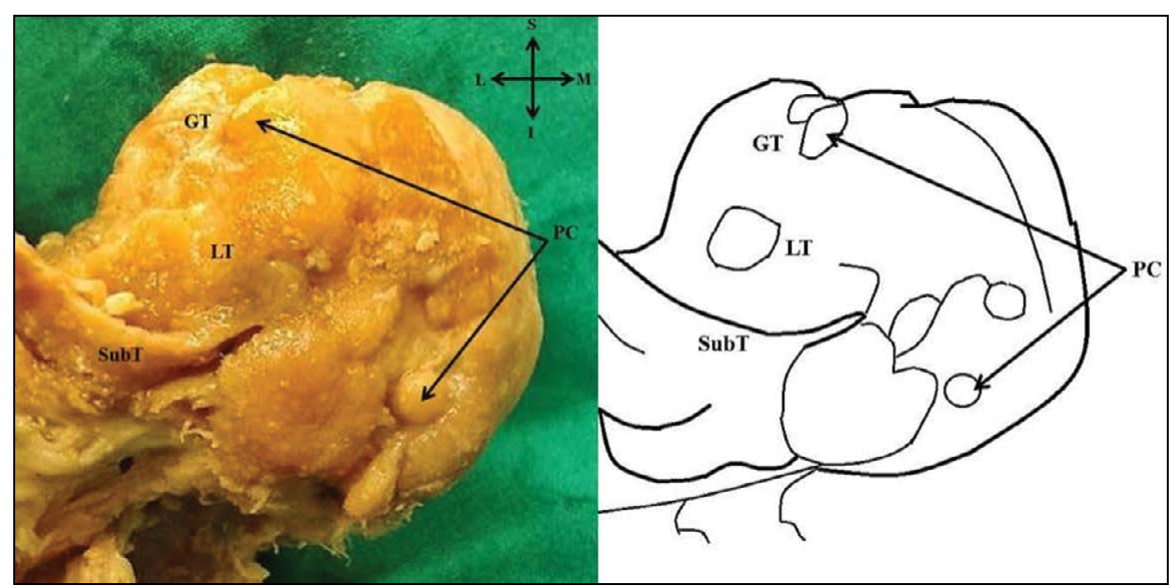

Figure 1. Anterior view of right proximal humerus illustrating protuberances and crests; GT — greater tuberosity; I — inferior; L — lateral; LT — lesser tuberosity; M — medial; PC — protuberances and crests; S - superior; SubT — tendon of subscapularis.

upon radiological examination and in human cadaveric and dry skeletal specimens [11]. Bioarchaelogists are intrigued by the multitude of factors and processes that are responsible for the development of enthesopathies.

\section{CASE REPORTS}

During routine cadaveric dissection at the Department of Clinical Anatomy at the University of KwaZulu-Natal, two cases of osteophytic enthesopathy were identified.

\section{Case 1}

An 85-year-old Caucasian female presented with varying degrees of circumscribed protuberances and crests spanning the area of the lesser and greater tuberosities of the right humeral head (Fig. 1). The subscapularis muscle was ossified most distally at the tendinous insertion to the lesser humeral tuberosity. Furthermore, the muscular belly and tendinous parts of the supraspinatus muscle were absent (Fig. 2).

\section{Case 2}

A relatively large bony spur/enthesophyte was reported in a 91-year-old Caucasian female. It appeared to protrude supero-medially from the proximal aspect of the right humerus, situated merely inferior to the surgical humeral neck (Fig. 3). Subsequently, the distal half of the supraspinatus muscle was completely ossified.

\section{DISCUSSION}

The "activity-specific" nature of the upper limb osteology is the focal point in bioarchaeology for the geo-social exploration of ancient human civilizations [11, 14, 21]. Recent studies have redefined the enthesis as an organ comprising of interconnected anatomical tissue performing the common function of stress dissipation [15, 20]. This "enthesis organ" concept suggests that the pressure exerted at the enthesis will disseminate to adjacent structures [5].

This report describes two cases of enthesopathy observed in two females over the age of 80 . Since there was no known record of any pathology premortem, it was understood that both individuals died as a result of natural causes. Despite the difference in morphology, both enthesopathies were described as osteophytic due to the proliferative nature. In accordance with the classification scheme proposed by Benjamin et al. [2], both entheses observed in this study were fibrocartilaginous and subject to mechanically-related enthesopathies.

According to Shaibani et al. [19], Mariotti et al. [14] and Voudouris et al. [22], enthesopathy is considered to be a phenomenon of advancing age. Mariotti et al. [14] and Villotte et al. [21] stated that osteophytic enthesopathies are generally more pronounced in elderly individuals, a finding which reflected unilaterally in both cases of this report. As a result, Villotte et al. [21] reported that the incidence of enthesopathies were higher on the right side than on the left side. Although the frequency of enthesopathies is deemed to be greater in males, this report was notably focused on females [14]. During medieval times the presence of such sex differences was attributed to the conventional "man the hunter vs. woman the gatherer" labour division [14]. 


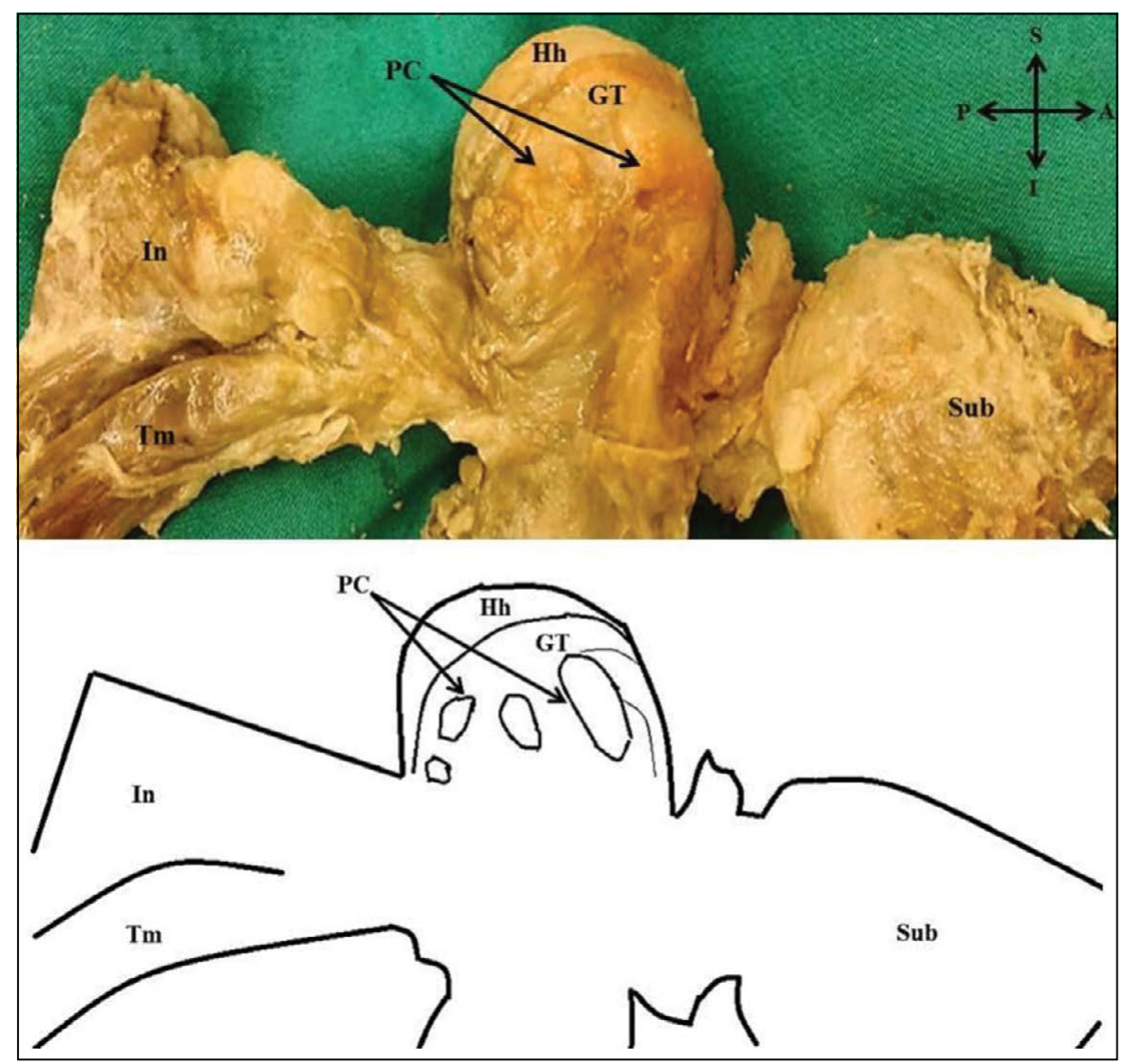

Figure 2. Lateral view of right proximal humerus demonstrating the absence of the supraspinatus muscle-tendon complex; $\mathrm{A}$ - anterior; GT — greater tuberosity; Hh — humeral head; I — inferior; In — infraspinatus muscle; P — posterior; PC — protuberances and crests; $\mathrm{S}$ - superior; Sub — subscapularis muscle; Tm — teres minor muscle.

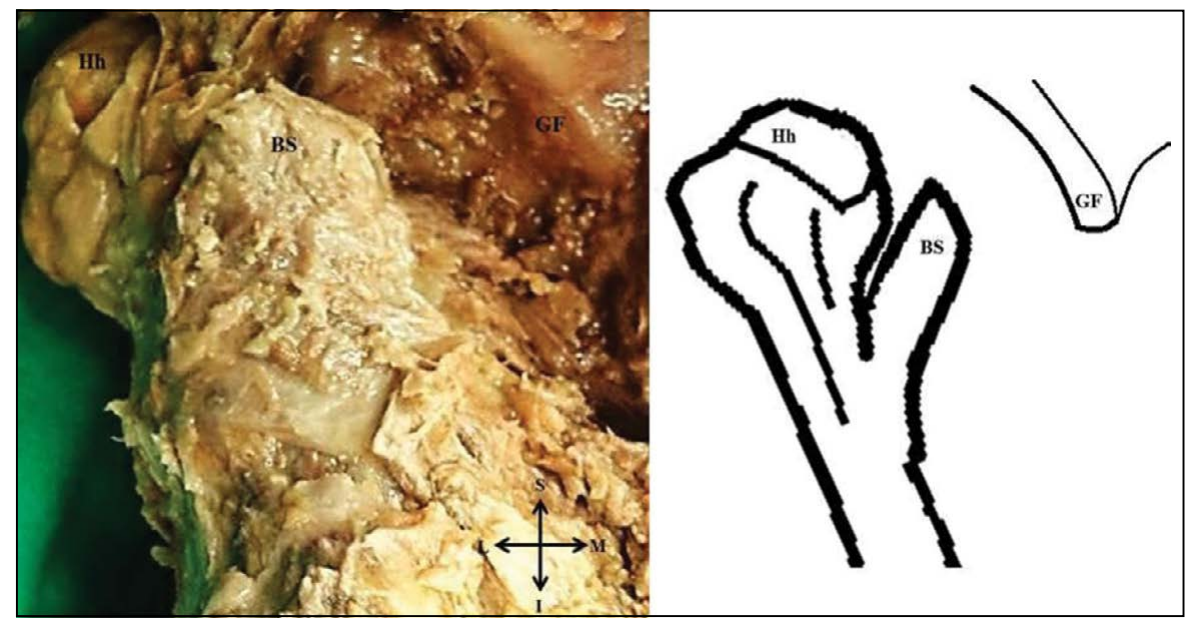

Figure 3. Anterior view of right proximal humerus illustrating the bony spur; BS — bony spur; GF — glenoid fossa; Hh — humeral head; $\mathrm{I}$ - inferior; L — lateral; $\mathrm{M}$ - medial; S - superior.

Contrary to the correlative relationship between osteolytic changes and tendon tears established by Bianchi et al. [7], Cormick [8] described the develop- ment of tendon tears to be caused by enthesopathy and subsequent loss of tendon impliability. Despite the well-defined functional-anatomic unit formed 
by the rotator cuff, the glenohumeral joint is subject to a great degree of pathology $[16,18]$. A magnetic resonance imaging study conducted by Lambert et al. [13] confirmed that rotator cuff tears originate from the insertion site of the supraspinatus tendon. Subsequently, Henderson [11] reported the frequency of enthesopathy at the enthesis of the supraspinatus tendon to be $83 \%$. This relatively high incidence may account for the defined protuberances and crests dispersed throughout the greater humeral tuberosity, specifically at the supraspinatus insertion site, observed in Case 1. Mariotti et al. [14] observed a similar skeletal pattern at the entheses of the ulnar collateral ligament and common flexor attachment on the medial humeral epicondyle. Case 2 was considered to be characteristic of a typical enthesopathy due to the location of the supero-medial enthesophyte at the periphery of the proximal humerus [21]. Histological studies suggest that an enthesophyte is in fact the combined result of a densely calcified area of fibrocartilage and the fusion of a number of bony nodules [6]. In view of Wolff's law, which states that bone will adapt and remodel when subjected to load and/or stress, it is understood that the enthesophyte region of a cancellous long bone remarkably develops into cortical bone [6].

In the present report, the distinct osteophytic differences in the morphology of the proximal humerus may be related to the repetitive stress forces exerted across the entheses during initiation of movement $[11,12,14]$. Osteophytic changes of glenohumeral skeletal remains may thus provide a palaeopathological diagnosis characteristic of rotator cuff disease $[2,18]$.

Many studies have discussed the occurrence of enthesopathy as a "disease-specific lesion" [11, 14, 22]. Disease processes of the seronegative spondyloarthropathy class, i.e. a range of arthropathies, reflect skeletal manifestations typical of enthesopathy and are especially significant in modern-day populations due to the socio-economic transformation [10, 11, 22]. Subsequently, Benjamin and McGonagle [5] emphasized the role and identification of abnormal osteological features at fibrocartilaginous entheses; the nature of which was seen in both cases of this report; as these are generally associated with diseases of the seronegative spondyloarthropathy class. Osteophytic and osteolytic enthesopathies of the humeral tuberosities may be characteristic of acromegaly and hyperparathyroidism, respectively [11]. The protrusion of the bony spur observed in Case 2 may be considered an inflammatory response to healing caused by bony and cartilaginoid ossification at the site in question [22].

\section{CONCLUSIONS}

Despite the "spontaneous" occurrence of such unique skeletal manifestations, it is evident that enthesopathies are reflective of underlying pathology. The entheses clearly provides far more than mere insertion to a structure, it may be an indicator of a spectrum of abnormally functioning factors and processes that are either disease-specific or bone-site specific. The reporting of these phenomena in clinical literature may assist the clinician and radiologist with a definite diagnosis and treatment. This invaluable contribution to the field of bioarchaeology may facilitate the skilful remodel of the lifestyle of ancient populations. Furthermore, the recognition and knowledge of glenohumeral enthesopathies may prevent a cascade of degenerative changes which follow rotator cuff pathology.

\section{REFERENCES}

1. Baumgarten DA, Taylor AT. Enthesopathy associated with seronegative spondyloarthropathy: $99 \mathrm{mTc}$-methylene diphosphonate scintigraphic findings. AJR Am J Roentgenol. 1993; 160(6): 1249-1250, doi: 10.2214/ ajr.160.6.8498227, indexed in Pubmed: 8498227.

2. Benjamin M, Evans EJ, Copp L. The histology of tendon attachments to bone in man. J Anat. 1986; 149: 89-100, indexed in Pubmed: 3693113.

3. Benjamin M, Kumai T, Milz S, et al. The skeletal attachment of tendons--tendon "entheses". Comp Biochem Physiol A Mol Integr Physiol. 2002; 133(4): 931-945, indexed in Pubmed: 12485684.

4. Benjamin M, McGonagle D. The anatomical basis for disease localisation in seronegative spondyloarthropathy at entheses and related sites. J Anat. 2001; 199(Pt 5): 503-526, indexed in Pubmed: 11760883.

5. Benjamin $M$, McGonagle $D$. The enthesis organ concept and its relevance to the spondyloarthropathies. Adv Exp Med Biol. 2009; 649: 57-70, indexed in Pubmed: 19731620.

6. Benjamin M, Toumi H, Suzuki D, et al. Evidence for a distinctive pattern of bone formation in enthesophytes. Ann Rheum Dis. 2009; 68(6): 1003-1010, doi: 10.1136/ ard.2008.091074, indexed in Pubmed: 18625624.

7. Bianchi S, Martinoli C, Abdelwahab IF. Ultrasound of tendon tears. Part 1: general considerations and upper extremity. Skeletal Radiol. 2005; 34(9): 500-512, doi: 10.1007/s00256-005-0956-1, indexed in Pubmed: 15999281.

8. Cormick W. Enthesopathy - a personal perspective on its manifestations, implications and treatment. Australas J Ultrasound Med. 2010; 13(4): 19-23, doi: 10.1002/j.22050140.2010.tb00174.x, indexed in Pubmed: 28191092. 
9. DiGangi EA, Moore MK. Methods in Human Skeletal Biology. Elsevier, United States of America 2013: 87-88.

10. Freemont AJ. Enthesopathies. Current Diagnostic Pathology. 2002; 8(1): 1-10, doi: 10.1054/cdip.2001.0089.

11. Henderson $C$. When hard work is disease: the interpretation of enthesopathies. Bar International Series. 2008; 1743(17).

12. Henderson $C Y$, Gallant AJ. Quantitative recording of enthesis. Paleopathol Newsletter. 2007; 137: 7-12.

13. Lambert RGW, Dhillon SS, Jhangri GS, et al. High prevalence of symptomatic enthesopathy of the shoulder in ankylosing spondylitis: deltoid origin involvement constitutes a hallmark of disease. Arthritis Rheum. 2004; 51(5): 681-690, doi: 10.1002/art.20681, indexed in Pubmed: 15478149

14. Mariotti V, Facchini F, Belcastro MG. Enthesopathies-proposal of a standardized scoring method and applications. Coll Antropol. 2004; 28(1): 145-159, indexed in Pubmed: 15636072.

15. McGonagle D. Imaging the joint and enthesis: insights into pathogenesis of psoriatic arthritis. Ann Rheum Dis. 2005; 64 Suppl 2: ii58-ii60, doi: 10.1136/ard.2004.034264, indexed in Pubmed: 15708939.

16. Morag $Y$, Jacobson JA, Miller B, et al. MR imaging of rotator cuff injury: what the clinician needs to know. Radiographics. 2006; 26(4): 1045-1065, doi: 10.1148/rg.264055087, indexed in Pubmed: 16844931.

17. Resnick D, Niwayama G. Entheses and enthesopathy. Anatomical, pathological, and radiological correlation.
Radiology. 1983; 146(1): 1-9, doi: 10.1148/radiology.146.1.6849029, indexed in Pubmed: 6849029.

18. Roberts AM, Peters TJ, Brown KR. New light on old shoulders: palaeopathological patterns of arthropathy and enthesopathy in the shoulder complex. J Anat. 2007; 211(4): 485-492, doi: 10.1111/j.1469-7580.2007.00789.x, indexed in Pubmed: 17711424.

19. Shaibani A, Workman R, Rothschild BM. The significance of enthesopathy as a skeletal phenomenon. Clin Exp Rheumatol. 1993; 11(4): 399-403, indexed in Pubmed: 8403585.

20. Slobodin G, Rozenbaum M, Boulman N, et al. Varied presentations of enthesopathy. Semin Arthritis Rheum. 2007; 37(2): 119-126, doi: 10.1016/j.semarthrit.2007.01.004, indexed in Pubmed: 17350676.

21. Villotte S, Castex D, Couallier V, et al. Enthesopathies as occupational stress markers: evidence from the upper limb. Am J Phys Anthropol. 2010; 142(2): 224-234, doi: 10.1002/ajpa.21217, indexed in Pubmed: 20034011.

22. Voudouris KP, Sidiropoulos P, Vounotripidis P, et al. Enthesial fibrocartilage - bone interaction: a radiographic study of selected sites of nonsynovial peripheral enthesopathy. J Musculoskelet Neuronal Interact. 2003; 3(1): 89-100, indexed in Pubmed: 15758371.

23. Zumwalt $A$. The effect of endurance exercise on the morphology of muscle attachment sites. J Exp Biol. 2006; 209(Pt 3): 444-454, doi: 10.1242/jeb.02028, indexed in Pubmed: 16424094. 